\title{
Health behaviour changes and onset of chronic health problems in later life
}

\author{
Marijke Veenstra and Astri Syse \\ Norsk institutt for forskning om oppvekst, velferd og aldring (NOVA) \\ Correspondence: Marijke Veenstra, e-mail: mve@nova.no, telephone: +4722541261
}

\begin{abstract}
Objectives: To assess five-year changes in health behaviours in later life and associations with onset of chronic health problems. The results may inform policy and interventions to promote healthy life years in ageing populations.

Methods: Data are derived from the Norwegian study on Life-course, Ageing and Generation (NorLAG), a five-year (2002-2007) panel survey comprising a nation wide community sample. The present analyses include a sample of 1,019 respondents aged 60 years and older. Five-year changes in smoking, alcohol use, physical exercise and Body Mass Index (BMI) are assessed according to prevalent and incident chronic health problems. Multivariate logistic analyses of "healthy" behavioural changes are conducted.

Results: A total of 453 respondents (45\%) reported at least one chronic condition and $13 \%(\mathrm{~N}=133)$ reported onset of chronic conditions in the course of the past five years. Over a five-year period, there was an overall reduction in smoking rates and a decrease in regular physical activity. Alcohol consumption in older people slightly increased over time, but the incidence of chronic health problems tended to reduce alcohol intake. Older persons experiencing chronic health problems were less likely to initiate physical activity.

Conclusions: The results provide limited support for the assumption that the onset of a chronic health condition triggers improved health behaviours. This suggests that the health care system could do more in targeting a potential "window of opportunity" for individuals to adopt new healthy behaviours in later life.
\end{abstract}

\section{INTRODUCTION}

Life style diseases such as cardiovascular diseases (CVD), diabetes, cancers, obstructive pulmonary disease (COPD), and musculoskeletal diseases are among the most common causes of reduced healthy life years in elderly Norwegians today (1). The prevalence of these conditions has increased over time in line with the ageing of the population and has resulted in an increased emphasis on health behaviours as important modifiable risk factors for prevention. Research has firmly established that smoking, physical inactivity, obesity and high alcohol consumption are among the most important adverse behavioural determinants of health (2-5). Current cohorts of elderly Norwegians have relatively higher alcohol consumption and obesity rates than previous cohorts $(6,7)$. Proportions with frequent (at least twice a month) alcohol consumption among persons 60-79 years increased from 29\% in 1995 to $57 \%$ in 2008 (7). Smoking rates in older age groups, on the other hand, have declined from $28 \%$ in 1997 to $21 \%$ in 2011 (8) and relatively fewer persons are physically inactive: $32 \%$ in 2001 compared to $17 \%$ in 2007 (9). Thus, there is evidence of both positive and negative health behaviour trends in different cohorts of Norwegian elders.

Longitudinal studies on long-term changes in health behaviours in older age groups are rare, and there is limited knowledge of the extent to which individuals change their health behaviours following a recent onset of a chronic health problem. The onset of a chronic condition may yield the necessary impetus for changes in unhealthy behaviours, which is relevant for secondary prevention policies (10). For example, smoking cessation in middle aged and older people is more likely after a critical change in health status (10-15). Further, individuals with heart disease and stroke are found to have a greater likelihood of smoking cessation, reduced alcohol consumption and increased physical exercise $(11,16)$.

There are many different behavioural theories, but the majority tend to underline the importance of similar factors. Fishbein therefore proposed an integrative model of behaviour, emphasizing the importance of underlying beliefs about the positive effects of the behaviour in question as well as perceptions about one's skills and abilities to perform the behaviour (17). In line with this model, one can assume that the "onset of chronic illness should motivate lifestyle changes because of increased awareness or because of strong subjective norms favouring changing behaviour" (18). However, even after the onset of a chronic condition it can be difficult to make lifestyle changes, as behaviours have become "entrenched habits by middle and older age" (18). Among the barriers to smoking cessation by older people is the concept of "damage done" and that of smoking being an "integral part" of an older person's life. Also, the onset of a chronic health problem may pose physical or psychological burdens (e.g. fatigue, nausea) that may obstruct maintaining or initiating new activity levels. As such, people's sense of control may be an important factor in predicting variability in changes in health behaviour following a chronic condition (19). A strong sense of control is 
associated with better adjustment to chronic illness and is considered a motivational force that activates individuals to engage in health-promoting behaviours.

The aim of the present article is two-fold: (1) To assess five-year changes in health behaviours in a community sample of persons 60 years and older; and (2) to address the association between the onset of chronic health problems and changes in health behaviours. The role of sense of control as well as potentially confounding covariates such as age, gender, educational background, and marital status will also be assessed. Factors related to an increase in specific types of health behaviours are likely to vary from factors related to the maintenance of such behaviours. The main focus in the present paper is therefore on behaviours that can be deemed "healthier" when faced with the onset of a chronic health problem: smoking cessation, reduced alcohol consumption, and increased physical activity.

\section{METHODS}

Panel data have been derived from the NorLAG study (20,21). In 2001, a stratified community sample was drawn from 8,298 adults aged 40-79 years in 30 municipalities in Norway. The first wave of data (T1) was collected during 2002 and 2003 by Statistics Norway and consisted of an initial telephone interview followed by a postal questionnaire. In addition, data from public registers (the Population register, Tax and income register, National database on education, Birth register, and Statistics Norway's events database (FDtrygd)), were linked to individual survey data. Participation and linkage to public register data was based on informed consent. A total of 5,559 persons responded to the telephone interview $(67 \%)$ and 4,149 of these returned the postal questionnaire $(75 \%)$. The second wave of data (T2) was collected five years later (20072008) and included the initial gross sample. Data collection procedures were similar at T1 and T2. A total of 3,774 respondents participated in both waves. Of those who participated at T1, 265 persons had died and 25 persons had moved abroad. Further details of the NorLAG design, sampling procedures, data collection, and response rates are available elsewhere $(20,21)$.

In the analyses of the present paper we only use the responses of 1,019 persons aged 60 years and older and who also responded to the telephone interview and the postal questionnaire in both waves of data collection. These constitute approximately $31 \%$ of the gross sample for this age group. Respondents with itemnonresponse on the particular health behaviour variables were excluded from the respective subanalyses. Hence, the numbers of cases in the different analyses varies slightly across dependent variables.

\section{Measures}

Health behaviours were measured through the postal questionnaire. Respondents' self-reported smoking be- haviour was assessed at both waves with the question: Do you use, or have you used, .... cigarettes? In the present paper we combined the original responses into a three-category variable "Never"; "Former smoker"; and "Current smoker (rarely to daily)". Responses of those indicating "Never" at T2 but one of the other categories at $\mathrm{T} 1$ were recoded according to their responses at T1. Alcohol consumption was measured with the question Consider your alcohol consumption the past 12 months. About how often have you consumed alcohol? Count even the times you only drank a little. No standard agreement exists regarding the level of consumption which constitutes hazardous drinking, and studies suggest that any level of alcohol consumption may carry risks (22). We distinguish between three categories "Never or not the last year"; "Less than weekly but at least the last year"; "Weekly or more". As such we apply a relatively modest definition of high alcohol intake, accounting for the potential underreporting of alcohol consumption that characterizes survey research $(23,24)$.

Respondents' physical activity levels were measured by aggregating responses to three different questions. About how often do you do the following? (1) In-door training (training studio, aerobics, gymnastics, etc.); (2) Tracking or training out-door (walks, bicycle rides, skiing etc.); (3) Gardening (in the season). Responses ranged from Daily (1) to Never (6). Respondents indicating at least weekly in-door training, daily outdoor training/tracking or daily gardening were considered physically active on a regular basis. This procedure is in line with research suggesting that the recommended 30 minutes or more of moderate intensity physical activity can be accumulated from walking, gardening, housework etc. Such an "active living" approach is considered particularly appropriate for older adults (25).

Body Mass Index (BMI) was calculated based on self-reported height and weight in the postal questionnaire. We used WHO defined categories of BMI, calculated as weight $(\mathrm{kg}) /$ height $\left(\mathrm{m}^{2}\right)$, with: underweight $(<18.5)$, normal weight (18.5-24.9), overweight (25-29.9), and obese ( $\geq 30)(26)$.

Chronic health problems were assessed at $\mathrm{T} 2$ through the telephone interview with the question: " $D o$ you have a long term illness, chronic health problem or disability" (Yes/No). If yes, respondents could freely mention up to three chronic conditions. Statistics Norway recoded their responses afterwards, according to ICD-10 classification (27). For each condition respondents were asked to report its year of onset. For the purpose of the present study, we label conditions arising between the two waves of data collection as incident chronic health problems indicating recent onset of chronic condition(s). The final variable consists of three categories: (1) No chronic health problem; (2) Incident chronic health problem(s); and (3) Prevalent chronic health problem(s). The latter group comprises individuals with pre-existing conditions at $\mathrm{T} 1$. A total 
of 453 respondents (45\%) reported at least one chronic condition and $14 \%(\mathrm{~N}=146)$ reported more than one condition. All in all, 133 (13\%) respondents indicated an incident chronic health problem between $\mathrm{T} 1$ and T2. The most frequently reported chronic conditions were musculoskeletal disorders $(\mathrm{N}=147)$, diseases of the circulatory system (including high blood pressure, $\mathrm{N}=140)$, diabetes $(\mathrm{N}=73)$ and cancers $(\mathrm{N}=30)$.

\section{Covariates}

Sense of personal control was measured with the Personal Mastery Scale (PMS) (28), which measures the extent to which individuals regard their life-chances as being under their own control in contrast to being fatalistically ruled. The PMS consists of 7 items with responses measured on a 5-point Likert scale, ranging from strongly agree to strongly disagree. In the first wave of NorLAG, the first two items were collected through the telephone interview and the remaining five items were collected through the postal questionnaire. Two of the items are positively phrased. The items were aggregated into a single sum score, which may vary between 7 and 35 with higher scores indicating superior feelings of sense of control.

Potentially confounding covariates included in the analyses of the present paper were age, gender, educational level (basic, secondary, higher), and marital status $(0=$ no partner; $1=$ married or cohabiting with partner). Educational level was obtained through the public registers by the Norwegian Standard Classification of Education for 2001, with levels below 3 being classified as "basic", levels 3 to 5 were classified as "secondary", and levels 6 to 8 were classified as "higher" education. For all covariates, T1 scores were used in the analyses.

Statistical analyses: Descriptive statistics were used to compare characteristics associated with attrition in the second wave and to present sample characteristics. $\mathrm{McNemar}$ tests for one-sample dependent observations were used to describe five-year changes in the categorical health behaviour variables and a paired t-test was applied to describe changes in BMI-units. Multivariate logistic analyses of "healthy" behavioural changes were conducted to assess associations with chronic health conditions, sense of control and potential confounding covariates. We used general linear models (GLM) for repeated measures to assess the associations between these covariates and five-year changes in BMI. Level of statistical significance was set at 5\%. All analyses were conducted with SPSS version 19.

\section{RESULTS}

Compared to those who responded to the telephone and postal questionnaires at both waves $(\mathrm{N}=1,019)$, respondents who did not participate in the follow-up survey or did not respond to the postal questionnaire in $2007(\mathrm{~N}=1,334)$ were older (70.2 vs. 67.5 years), more likely to rate their health as poor ( $18.1 \%$ vs. $6.6 \%)$, more likely to have lower education ( $42.7 \%$ vs. $18.3 \%)$, more likely to smoke (33.2\% vs. $22.3 \%$ p $<0.001)$, less physically active (15.1\% vs. $23.2 \%$ ), and had a relatively higher alcohol consumption (71.3\% vs. $57.5 \%)$. An overview of sample characteristics for these 1,019 respondents is presented in Table 1 .

Table 2 describes the distribution of health behaviour variables by chronic health problems and sociodemographic characteristics. The percentages of male and female smokers were similar (23 vs. $22 \%$ ), but a larger proportion of men had smoked previously. Men also had higher alcohol consumption than women. Differences across levels of education were statistically significant for all four health behaviours. Smoking and inactivity were more common among persons with a basic education, whereas alcohol consumption was higher among those with a higher education. Older respondents $(67+$ years at $\mathrm{T} 1)$ reported relatively lower smoking rates and less alcohol consumption than younger respondents (60-66). Respondents with a partner were less obese than those without a partner, and their smoking rates were also relatively lower. On the other hand, alcohol consumption was higher among respondents with a partner. Respondents with a chronic health problem did not differ significantly from healthy persons in smoking levels or physical activity levels, but they reported relatively lower alcohol consumption and somewhat higher levels of obesity.

Small but statistically significant correlations were found between the different types of health behaviour variables. Physical activity was associated with higher alcohol consumption (Spearman's rho=0.08), lower smoking rates (Spearman's rho $=-0.12$ ), and lower BMI (Spearman's rho $=-0.13)$. Higher alcohol consumption was also associated with higher smoking rates (Spearman's rho=0.15).

Table 1. Sample characteristics of persons 60 years and older (at T1) responding to the telephone survey and postal questionnaire at both waves of the NorLAG study $(\mathrm{N}=1,019)$.

\begin{tabular}{lrr}
\hline & $\mathbf{N}$ & $\mathbf{\%}$ \\
\hline Gender & & \\
$\quad$ Men & 507 & 49.8 \\
$\quad$ Women & 512 & 50.2 \\
Education (T1) & & \\
$\quad$ Basic & 188 & 18.4 \\
$\quad$ Secondary & 526 & 51.6 \\
$\quad$ Higher & 300 & 29.4 \\
$\quad$ Unknown & 5 & 0.5 \\
Age (T1) & & \\
$\quad$ 60-66 & 509 & 50 \\
$\quad$ 67+ & 510 & 50 \\
Marital status (T1) & & \\
$\quad$ No partner & 329 & 32.3 \\
$\quad$ Partner & 690 & 67.7 \\
Chronic health problem (T2) & & \\
$\quad$ None & 566 & 55.5 \\
$\quad$ Incident (onset later T1 interview) & 133 & 13.1 \\
$\quad$ Prevalent & 320 & 31.4 \\
\hline
\end{tabular}


Table 2. Distribution of health behaviours at $\mathrm{T} 1$ across sociodemographic and health characteristics (percentages).

\begin{tabular}{|c|c|c|c|c|c|c|c|c|c|c|c|c|c|c|c|}
\hline & \multicolumn{4}{|c|}{ Smoking behaviour } & \multicolumn{3}{|c|}{ Physical activity } & \multicolumn{4}{|c|}{ Alcohol consumption } & \multicolumn{4}{|c|}{ Body Mass Index (BMI) } \\
\hline & $\begin{array}{c}\text { Never } \\
N=398\end{array}$ & $\begin{array}{l}\text { Former } \\
\text { smoker } \\
N=371\end{array}$ & $\begin{array}{l}\text { Current } \\
\text { smoker } \\
N=221\end{array}$ & $P$ & $\begin{array}{c}\text { Inactive } \\
N=187\end{array}$ & $\begin{array}{l}\text { Active } \\
N=810\end{array}$ & $P$ & $\begin{array}{c}\text { Weekly } \\
\text { or more } \\
N=430\end{array}$ & $\begin{array}{c}\text { Less than } \\
\text { weekly } \\
N=444\end{array}$ & $\begin{array}{c}\text { Rarely or } \\
\text { never } \\
N=137\end{array}$ & $P$ & $\begin{array}{c}\text { Normal } \\
N=446\end{array}$ & $\begin{array}{c}\text { Over- } \\
\text { weight } \\
N=428\end{array}$ & $\begin{array}{c}\text { Obese } \\
N=114\end{array}$ & $P$ \\
\hline Gender & & & & $* * *$ & & & & & & & $* * *$ & & & & $*$ \\
\hline Men & $32.6 \%$ & $44.8 \%$ & $22.6 \%$ & & $20.9 \%$ & $79.1 \%$ & & $50.4 \%$ & $40.7 \%$ & $8.9 \%$ & & $44.5 \%$ & $46.5 \%$ & $9.0 \%$ & \\
\hline Women & $47.7 \%$ & $30.3 \%$ & $22.0 \%$ & & $16.6 \%$ & $83.4 \%$ & & $34.7 \%$ & $47.1 \%$ & $18.1 \%$ & & $46.0 \%$ & $39.9 \%$ & $14.1 \%$ & \\
\hline Education & & & & $* *$ & & & $* * *$ & & & & $* * *$ & & & & $* *$ \\
\hline Basic & $41.1 \%$ & $27.8 \%$ & $31.1 \%$ & & $27.0 \%$ & $73.0 \%$ & & $17.6 \%$ & $61.5 \%$ & $20.9 \%$ & & $41.9 \%$ & $46.2 \%$ & $11.8 \%$ & \\
\hline Secondary & $38.2 \%$ & $40.7 \%$ & $21.1 \%$ & & $19.3 \%$ & $80.7 \%$ & & $39.5 \%$ & $46.7 \%$ & $13.8 \%$ & & $42.9 \%$ & $42.7 \%$ & $14.3 \%$ & \\
\hline Higher & $43.9 \%$ & $37.1 \%$ & $19.0 \%$ & & $12.5 \%$ & $87.5 \%$ & & $63.0 \%$ & $28.6 \%$ & $8.4 \%$ & & $51.0 \%$ & $42.5 \%$ & $6.5 \%$ & \\
\hline Age & & & & $* * *$ & & & & & & & & & & & \\
\hline $60-66$ & $38.6 \%$ & $34.2 \%$ & $27.1 \%$ & & $19.7 \%$ & $80.3 \%$ & & $48.0 \%$ & $41.6 \%$ & $10.4 \%$ & $* * *$ & $45.3 \%$ & $42.5 \%$ & $12.2 \%$ & \\
\hline $67+$ & $42.1 \%$ & $41.4 \%$ & $16.4 \%$ & & $17.8 \%$ & $82.2 \%$ & & $35.8 \%$ & $46.8 \%$ & $17.4 \%$ & & $45.2 \%$ & $44.1 \%$ & $10.6 \%$ & \\
\hline Marital status & & & & $*$ & & & & & & & $* *$ & & & & $*$ \\
\hline No partner & $41.7 \%$ & $32.3 \%$ & $26.0 \%$ & & $18.8 \%$ & $81.2 \%$ & & $35.6 \%$ & $46.9 \%$ & $17.5 \%$ & & $45.1 \%$ & $39.8 \%$ & $15.0 \%$ & \\
\hline Partner & $39.5 \%$ & $39.9 \%$ & $20.6 \%$ & & $18.7 \%$ & $81.2 \%$ & & $45.8 \%$ & $42.5 \%$ & $11.7 \%$ & & $45.3 \%$ & $44.9 \%$ & $9.8 \%$ & \\
\hline Chronic health problem & & & & & & & & & & & $* * *$ & & & & $* *$ \\
\hline None & $38.9 \%$ & $36.9 \%$ & $24.2 \%$ & & $17.8 \%$ & $82.2 \%$ & & $47.6 \%$ & $42.5 \%$ & $9.9 \%$ & & $48.9 \%$ & $42.9 \%$ & $8.2 \%$ & \\
\hline $\begin{array}{l}\text { Incident (onset later } \\
\mathrm{T} 1 \text { interview) }\end{array}$ & $45.8 \%$ & $34.4 \%$ & $19.8 \%$ & & $18.6 \%$ & $81.4 \%$ & & $36.8 \%$ & $42.1 \%$ & $21.1 \%$ & & $38.2 \%$ & $47.3 \%$ & $14.5 \%$ & \\
\hline Prevalent & $40.1 \%$ & $39.8 \%$ & $20.1 \%$ & & $20.6 \%$ & $79.4 \%$ & & $35.9 \%$ & $47.3 \%$ & $16.8 \%$ & & $41.8 \%$ & $42.1 \%$ & $16.1 \%$ & \\
\hline
\end{tabular}

$\chi^{2}$ test: $* P \leq 0.05 ; * * P \leq 0.01 ; * * * P \leq 0.001$

Table 3 presents five-year changes in health behaviours for the entire sample of people aged $60+$ years at $\mathrm{T} 1$ and according to prevalent and incident chronic health problems at T2. Only persons with valid responses in both waves were included. In the entire sample, five-year changes in all four health behaviour variables were statistically significant at the $5 \%$ level. Largest changes were found for smoking behaviour where 95 persons who indicated that they were smokers at $\mathrm{T} 1$ reported that they were none-smokers at T2. This corresponds to an approximately $10 \%$ decrease in the total sample. Also, 124 persons indicated that they were physically active at $\mathrm{T} 1$, but had become inactive at $\mathrm{T} 2$, the latter corresponding to a $13 \%$ decrease in regular physical activity. There was a slight increase over time in proportions of respondents who were obese and consumed alcohol at a weekly basis. Stratifying the sample according to prevalent and incident chronic health problems indicated a significant decline in smoking rates and a decrease in physical activity. Among those with an incident chronic health problem there was a tendency of declining alcohol consumption, but the changes were not statistically significant.

At the first wave, 211 respondents 60 years and older were classified as smokers and $45 \%(\mathrm{~N}=95)$ quit over the subsequent five years. Multivariate logistic regression analysis showed that neither chronic health conditions nor sense of control predicted smoking cessation in this sample of older Norwegians (Table 4). Only the association with age was statistically significant $(\mathrm{B}=0.07 ; \mathrm{P}=0.03)$, which may indicate that smoking cessation rates continue to increase with age also in late life.

A total of 187 respondents aged 60 years and older were classified as physically inactive at $\mathrm{T} 1$, and 76 of these were physically active five years later. Multivariate logistic regression analysis (Table 4) indicated that failing to increase activity among persons $60+$ years was associated with the prevalence of a chronic health problem. Incidence of a chronic health problem showed the same tendency but results were not statistically significant $(\mathrm{P}=0.069)$. A similar multivariate analysis based on physically active respondents at $\mathrm{T} 1$ indicated that maintaining regular levels of activity was associated with a higher sense of control $(\mathrm{B}=0.08 ; \mathrm{P}=0.002)$ (data not shown but available on request).

At T1, 352 respondents (85\%) indicated high weekly alcohol consumption. Five years later, 63 of these reported lower levels of alcohol consumption. Multivariate logistic regression analysis indicated a tendency towards reduced alcohol consumption among persons experiencing an incident chronic health condition, but this association was not statistically significant at the $5 \%$ level $(\mathrm{P}=0.056)$. A reduction in alcohol consumption was more likely in older age groups. Respondents with a higher education were less likely to reduce their alcohol consumption (Table 4).

At $\mathrm{T} 1,114$ respondents $(11 \%)$ were classified as obese. Five years later, 30 of these belonged to lower BMI categories (overweight and normal). A multivariate GLM analysis for repeated measures revealed a small but statistically significant decrease in BMI over five years (within subjects effect Time: $F=7.99$; $\mathrm{P}<0.01)$. In addition, five-year changes in BMI differed across gender (Time*Gender: $\mathrm{F}=4.69$ and $\mathrm{P}=0.031$ ) and age (Time*Age: $\mathrm{F}=14.12$ and $\mathrm{P}<0.001$ ). Whereas men on average reported 0.5 units increase in BMI, women reported about the same decrease. Self-reports indicated decreasing BMI in the highest age groups whereas BMI on average increased among the young- 
Table 3. Prevalence and five-year changes in health behaviour for the whole sample $60+$ years (T1) stratified according to prevalent and incident chronic health problems between $\mathrm{T} 1$ and T2; percentages (\%).

\begin{tabular}{|c|c|c|c|c|c|}
\hline & $\mathbf{N}$ & Prevalence & Increase & Decrease & Prevalence \\
\hline \multicolumn{6}{|l|}{ Smoking } \\
\hline Entire sample (valid at baseline \& follow-up) & 954 & 22.1 & 3.1 & 9.9 & $15.3^{* * *}$ \\
\hline No chronic health problem & 535 & 24.1 & 3.6 & 10.8 & $16.8^{* * *}$ \\
\hline Prevalent chronic health problem 2002-03 & 292 & 19.8 & 2.1 & 8.9 & $13.0^{* *}$ \\
\hline Incident chronic health problem 2003-07 & 127 & 18.9 & 3.9 & 8.7 & $14.2 *$ \\
\hline \multicolumn{6}{|l|}{ Physically active } \\
\hline Entire sample (valid at baseline $\&$ follow-up) & 941 & 81.5 & 8.1 & 13.2 & $76.4 * * *$ \\
\hline No chronic health problem & 530 & 82.1 & 10.0 & 11.7 & 80.4 \\
\hline Prevalent chronic health problem 2002-03 & 293 & 80.5 & 5.5 & 15.0 & $70.9^{* * *}$ \\
\hline Incident chronic health problem 2003-07 & 118 & 81.4 & 7.3 & 15.3 & $72.0 *$ \\
\hline \multicolumn{6}{|l|}{ High alcohol consumption } \\
\hline Entire sample (valid at baseline \& follow-up) & 981 & 42.3 & 8.8 & 9.9 & $43.2 *$ \\
\hline No chronic health problem & 550 & 47.6 & 8.0 & 8.5 & 48.5 \\
\hline Prevalent chronic health problem 2002-03 & 302 & 34.8 & 8.9 & 8.6 & 36.8 \\
\hline Incident chronic health problem 2003-07 & 129 & 37.2 & 11.6 & 18.6 & 35.7 \\
\hline \multicolumn{6}{|l|}{ Obesity (BMI) } \\
\hline Entire sample (valid at baseline \& follow-up) & 959 & 11.2 & 10.1 & 12.4 & $12.3^{*}$ \\
\hline No chronic health problem & 532 & 8.1 & 9.8 & 10.9 & 8.8 \\
\hline Prevalent chronic health problem 2002-03 & 301 & 14.9 & 9.9 & 12.9 & 16.3 \\
\hline Incident chronic health problem 2003-07 & 126 & 15.1 & 11.9 & 17.5 & 17.5 \\
\hline
\end{tabular}

McNemar Bowker test $* P \leq 0.05 ; * * P \leq 0.01 ; * * * P \leq 0.001$

Table 4. Logistic regression analyses of positive behavioural changes; unstandardized regression coefficients (B) and levels of statistical significance $(\mathrm{P})$.

\begin{tabular}{|c|c|c|c|c|c|c|}
\hline & \multicolumn{2}{|c|}{$\begin{array}{l}\text { Smoking cessation } \\
\qquad \mathrm{N}=207\end{array}$} & \multicolumn{2}{|c|}{$\begin{array}{l}\text { Increased physical activity } \\
\qquad \mathrm{N}=171\end{array}$} & \multicolumn{2}{|c|}{$\begin{array}{l}\text { Reduced alcohol consumption } \\
\qquad \mathrm{N}=409\end{array}$} \\
\hline & $\mathrm{B}$ & Sig. (P) & $\mathrm{B}$ & Sig. (P) & $\mathrm{B}$ & Sig. (P) \\
\hline Gender (Women) & -.480 & .119 & .693 & .069 & -.140 & .641 \\
\hline \multicolumn{7}{|l|}{ Education } \\
\hline Basic & ref & ref & ref & ref & ref & ref \\
\hline Secondary & -.200 & .955 & .634 & .120 & -.720 & .096 \\
\hline Higher & .728 & .079 & .588 & .252 & -1.701 & $<0.001$ \\
\hline Partner (yes) & .439 & .176 & .615 & .146 & -.479 & .125 \\
\hline Age (continuous) & .071 & .034 & -.024 & .463 & .057 & .032 \\
\hline Sense of control (7-35) & -.140 & .712 & -.052 & .148 & -.017 & .607 \\
\hline \multicolumn{7}{|l|}{ Chronic health problem } \\
\hline No & ref & ref & ref & ref & ref & ref \\
\hline Incident & .092 & .846 & -1.006 & .069 & .756 & .056 \\
\hline Prevalent & -.014 & .968 & -1.386 & $<0.001$ & .133 & 699 \\
\hline
\end{tabular}

est respondents (60-66 years). The analyses did not reveal a significant association between a change in BMI and chronic health problems or sense of control.

\section{Discussion}

The results of the present study indicate an overall reduction in smoking rates and a decrease in regular physical activity over five years in persons aged 60 years and older. Furthermore, although alcohol con- sumption in older people in general has increased slightly over time, incidence of chronic health problems tends to be associated with reduced alcohol consumption. In addition, our findings show that older persons experiencing chronic health problems are less likely to initiate physical activity. The results also indicate that a strong sense of control does not affect the likelihood for changing to "healthy" behaviours, but contributes to the maintenance of physical activity also in later life. Five-year changes in smoking cessa- 
tion, weight reduction, and reduced alcohol consumption are relatively more pronounced in older age groups. Age was not related to (changes in) physical activity in the present study, which is in line with the findings of a previous Norwegian cross-sectional study that indicated relatively similar levels of physical activity among adults until age 70 (29).

Our study further indicates that older persons with a higher education are less likely to reduce their alcohol intake, although they have the highest rates of alcohol consumption. Alcohol is a source of pleasure, relaxation and socializing for many (22). However, research results on the potentially protective health effects of light alcohol intake are mixed and by far not sufficient to suggest alcohol consumption for health reasons (30). Also, elderly people are the largest per capita consumers of prescription medication, which in many ways may interact negatively with alcohol (31).

Taken together, the results of the present study show limited support for the assumption that the onset of a chronic health condition triggers positive health behaviour changes. As such, our findings are in line with the recent study of Newsom (18). This suggests that the health care system could do more in targeting the potential window of opportunity for individuals to adopt healthier habits following the onset of chronic health problems (10,32-34). Other studies have for example pointed to clinician failure to promote smoking cessation in older people as a barrier to changes in health behaviour (35). Secondary prevention strategies may be particularly relevant in middle and older age groups where adverse health events are more likely to occur, and since elderly are increasingly likely to receive a major diagnosis or to be hospitalised as they age. Regardless of age, healthy behaviour changes can increase life expectancy and improve health and quality of life. There may, however, be a potential benefit of age-matched interventions, as factors that motivate behavioural change in older people may be different from those that motivate younger $(36,37)$. As most studies on health behaviour changes focus on individuals who are at least 30 years younger than the sample in the present study (38), there is still a lack of evidence of which interventions and preventive strategies constitute effective health promotion in later life. A previous randomised intervention study from Australia indicated positive effects on health behaviour (physical activity) and health in elderly people following a general practice education programme (39). This study emphasized the considerable public health impact of general practitioners on promoting health for elderly patients. A more recent primary care study from the UK (40) indicated that providing written advice to older patients alone is insufficient to improve shortterm health behaviour and suggests that sustained and direct professional/patient follow-up contact may be necessary to achieve benefit. In Norway, the need for research establishing this kind of evidence becomes increasingly relevant with the implementation of the
Coordination Reform which emphasizes the responsibility of the municipalities for early detection of treatment needs and for implementing secondary prevention strategies in order to postpone or avoid hospitalisation (41).

The present study is one of the first using large scale survey data on longitudinal changes in health behaviour among elderly Norwegians. Despite its large sample size, the sample is not fully representative of sub-groups of the community-dwelling elderly population in Norway. Due to selective attrition, our sample of respondents 60-79 years is higher educated compared to the population 60 years and older. Higher education is usually associated with more positive behavioural changes (18), suggesting that, without attrition, health behaviour would have been even more stable than as suggested by the present results. Furthermore, persons over 79 years in the first wave are not included and attrition is highest among those with seriously incapacitating diseases or health problems. The results therefore apply to home-dwelling, relatively healthy, elderly. Also, self reports on chronic health problems do not necessarily correspond to clinical diagnoses, and may range from mild symptoms to severe limitations. Hence, the results may refer to the association of relatively minor chronic health problems with health behaviour changes. On the one hand, this may have contributed to an underestimation of the associations between incident chronic health condition and changes in health behaviours. On the other hand, self-reported symptoms and conditions have shown to better reflect daily health status (42), which may be more relevant for subsequent health behaviour.

An important remaining question, which may be answered through subsequent data collections, is whether older people who improve their health behaviours following the onset of a chronic health problem also have lower risks of further adverse health events, new diagnoses, hospitalisations and/or early mortality.

\section{CONCLUSION}

The vast majority of older home-dwelling individuals do not change their health behaviour following the onset of a chronic health condition. This suggests that the health care system could do more in targeting a potential "window of opportunity" for individuals to adopt new healthy behaviours in later life. The results can be assumed quite robust though we must note the potential bias due to selective attrition inherent in large scale longitudinal surveys, especially in elderly populations. In line with the ageing of the population, high and increasing prevalence of chronic health conditions and limited change in health behaviours underscore the importance of developing effective secondary prevention strategies, such as behavioural interventions and chronic disease management approaches targeting middle and older age groups. 


\section{ACKNOWLEDGEMENTS}

This research was supported by a grant from the Research Council of Norway (grant no. 187783). The NorLAG and LOGG surveys are financed by the Research Council of Norway (grant no. 149564 and 168373), Ministry of Health and Care Services, Ministry of Labour, Ministry of Children,
Equality and Social Inclusion, Ministry of Local Government and Regional Development, NOVA and Statistics Norway. The LOGG and NorLAG datasets are part of the ACCESS Life Course infrastructure project funded by the National Financing Initiative for Research Infrastructure at the Research Council of Norway (grant no. 195403) and NOVA.

\section{REFERENCES}

1. Folkehelseinstituttet. Folkehelserapport 2010: Helsetilstanden i Norge. Rapport 2010: 2.

2. Khaw KT, Wareham N, Bingham S, Welch A, Luben R, Day N. Combined impact of health behaviours and mortality in men and women: The EPIC-Norfolk prospective population study. Plos Med 2008; 5 (3): 518.

3. Warburton DER, Nicol CW, Bredin SSD. Health benefits of physical activity: the evidence. CMAJ 2006; 174 (6): 801-9.

4. Klijs B, Mackenbach JP, Kunst AE. Obesity, smoking, alcohol consumption and years lived with disability: a Sullivan life table approach. BMC Public Health 2011; 11: 378.

5. Guh DP, Zhang W, Bansback N, Amarsi Z, Birmingham CL, Anis AH. The incidence of co-morbidities related to obesity and overweight: A systematic review and meta-analysis. BMC Public Health 2009; 9: 88.

6. Folkehelseinstituttet. Overvekt og fedme hos voksne - faktaark med statistikk. [cited 2012 May 3th]; Available from: http://www.fhi.no/eway/default.aspx?pid=233\&trg=MainArea_5661\&MainArea_5661=5631:0: 15,2689:1:0:0:::0:0.

7. Bye EK, Østhus S. Alkoholkonsum blant eldre. Hovedfunn fra spørreundersøkelser 1985-2008: SIRUS 2012.

8. Norgeshelsa Folkehelseinstituttet. Røykevaner, voksne - 3-årig gj.snitt. [cited 2012 May 3th]; Available from: http://www.norgeshelsa.no/norgeshelsa/?language=no.

9. Vaage OF. Tidsbruk og fritidsaktiviteter. In: Mørk E, editor. Seniorer i Norge 2010. Oslo/Kongsvinger: Statistisk Sentralbyrå, 2011.

10. Keenan PS. Smoking and weight change after new health diagnoses in older adults. Arch Intern Med 2009; 169 (3): $237-42$.

11. van Gool CH, Kempen GIJM, Penninx BWJH, Deeg DJH, van Eijk JTM. Chronic disease and lifestyle transitions - Results from the Longitudinal Aging Study Amsterdam. J Aging Health 2007; 19 (3): 416-38.

12. Wray LA, Herzog AR, Willis RJ, Wallace RB. The impact of education and heart attack on smoking cessation among middle-aged adults. J Health Soc Beh 1998; 39 (4): 271-94.

13. Clark A, Etile F. Do health changes affect smoking? Evidence from British panel data. J Health Econ 2002; 21 (4): 533-62.

14. Falba T. Health events and the smoking cessation of middle aged Americans. J Behav Med 2005; 28 (1): 2133.

15. Gjeilo KH, Stenseth R, Klepstad P, Lydersen S, Wahba A. Patterns of smoking behaviour in patients following cardiac surgery. A prospective study. Scand Cardiovasc J 2010; 44 (5): 295-300.

16. Twardella D, Loew M, Rothenbacher D, Stegmaier C, Ziegler H, Brenner H. The diagnosis of a smokingrelated disease is a prominent trigger for smoking cessation in a retrospective cohort study. J Clin Epidemiol 2006; 59 (1): 82-9.

17. Fishbein M, Yzer CM. Using theory to design effective health behavior interventions. Communication Theory $2003 ; 13$ (2): 164-83.

18. Newsom JT, Huguet N, McCarthy MJ, Ramage-Morin P, Kaplan MS, Bernier J, et al. Health behavior change following chronic illness in middle and later life. J Gerontol B Psychol Sci Soc Sci 2012; 67 (3): 279-88.

19. Skaff M. Sense of control and health: A dynamic duo in the aging process. In: Aldwin CM, Park CL, Spiro A, editors. Handbook of health psychology and aging. New York: The Guilford Press, 2007.

20. Holmøy A. Undersøkelse om livsløp, aldring og generasjon (LAG). Dokumentasjonsrapport. Oslo: Statistisk Sentralbyrå. Rapport: 2003/88.

21. Bjørshol E, Høstmark M, Lagerstrøm BO. Livsløp, generasjon og kjønn. LOGG 2007. Dokumentasjonsrapport. Oslo: Statistisk Sentralbyrå. Rapport: 19/2010.

22. Hallgren M, Högberg P, Andréasson S. Alcohol consumption among elderly European Union citizens. Health effects, consumption trends and related issues. Stockholm: Swedish National Institute of Public Health, 2009.

23. Horverak Ø, Bye EK. Det norske drikkemønsteret. En studie basert på intervjudata fra 1973 til 2004. Oslo: Statens Institutt for Rusmiddelforskning; 2007: 2.

24. Høyer G, NIlssen O, Brenn T, Schirmer H. Påliteligheten av selvrapportert alkoholkonsum. Svalbardstudien 1988-89. Norsk Epidemiologi 1996; 6 (1): 109-13. 
25. Berger U, Der G, Mutrie N, Hannah MK. The impact of retirement on physical activity. Ageing Soc 2005; 25: 181-95.

26. WHO. Obesity: preventing and managing the global epidemic. Report of a WHO consultation. Geneva: World Health Organization, 2000.

27. WHO. International Statistical Classification of Diseases and Related Health Problems. 10th Revision. Version for 2007. Geneva: World Health Organization, 2007.

28. Pearlin LI, Schooler C. The structure of coping. J Health Soc Behav 1978; 19 (1): 2-21.

29. Helsedirektoratet. Fysisk aktivitet blant voksne og eldre i Norge. Resultater fra en kartlegging i 2008 og 2009. Oslo, 2009: IS-1754.

30. Fillmore KM, Stockwell T, Chikritzhs T, Bostrom A, Kerr W. Moderate alcohol use and reduced mortality risk: Systematic error in prospective studies and new hypotheses. Ann Epidemiol 2007; 17 (5): S16-S23.

31. Moore AA, Whiteman EJ, Ward KT. Risks of combined alcohol/medication use in older adults. Am J Geriatr Pharmacother 2007; 5 (1): 64-74.

32. Fisher EB, Fitzgibbon ML, Glasgow RE, Haire-Joshu D, Hayman LL, Kaplan RM, et al. Behavior matters. Am J Prev Med 2011; 40 (5): E15-E30.

33. Lawson PJ, Flocke SA. Teachable moments for health behavior change: A concept analysis. Patient Educ Couns 2009; 76 (1): 25-30.

34. Cohen DJ, Clark EC, Lawson PJ, Casucci BA, Flocke SA. Identifying teachable moments for health behavior counseling in primary care. Patient Educ Couns 2011; 85 (2): e8-15.

35. Allen SC. What determines the ability to stop smoking in old age? Age Ageing 2008; 37 (5): 490-1.

36. Clark MA, Rakowski W, Kviz FJ, Hogan JW. Age and stage of readiness for smoking cessation. J Gerontol B-Psychol 1997; 52 (4): S212-S21.

37. Winkleby MA, Flora JA, Kraemer HC. A community-based heart disease intervention: predictors of change. Am J Public Health 1994; 84 (5): 767-72.

38. Kleykamp BA, Heishman SJ. The Older Smoker. JAMA 2011; 306 (8): 876-7.

39. Kerse NM, Flicker L, Jolley D, Arroll B, Young D. Improving the health behaviours of elderly people: randomised controlled trial of a general practice education programme. $\mathrm{Br}$ Med J 1999; 319 (7211): 683-7.

40. Harari D, Iliffe S, Kharicha K, Egger M, Gillmann G, Von Renteln-Kruse W, et al. Promotion of health in older people: a randomised controlled trial of health risk appraisal in British general practice. Age Ageing 2008; 37 (5): 565-71.

41. NOU. The Coordination Reform. Proper treatment - at the right place and right time. Norwegian Ministry of Health and Care Services 2008-2009; 47.

42. Basch E, Jia XY, Heller G, Barz A, Sit L, Fruscione M, et al. Adverse symptom event reporting by patients vs clinicians: Relationships with clinical outcomes. J Natl Cancer Inst 2009; 101 (23): 1624-32. 